\title{
Um resort na restinga de Maricá / RJ: modernização do território e destruição da pesca artesanal em uma área de proteção ambiental
}

Territorial modernisation and artisanal fishing: the construction of a tourist resort in an environmental protection area in Maricá (Rio de Janeiro) Modernisation territoriale et destruction de la pêche artisanale:

l'implémentation d'un village touristique dans une aire de protection environnementale à Maricá (Rio de Janeiro)

Modernización del territorio y destrucción de la pesca artesanal: la implantación de un resort en el área de protección ambiental de Marica-Río de Janeiro

\section{Erich Moura Soares de Souza}

\section{(2) OpenEdition}

\section{Journals}

\section{Edição electrónica}

URL: http://journals.openedition.org/espacoeconomia/1713

DOI: 10.4000/espacoeconomia.1713

ISSN: 2317-7837

\section{Editora}

Núcleo de Pesquisa Espaço \& Economia

\section{Refêrencia eletrónica}

Erich Moura Soares de Souza, « Um resort na restinga de Maricá / RJ: modernização do território e destruição da pesca artesanal em uma área de proteção ambiental », Espaço e Economia [Online], 6 | 2015, posto online no dia 09 agosto 2015, consultado o 14 novembro 2019. URL : http:// journals.openedition.org/espacoeconomia/1713; DOI : 10.4000/espacoeconomia.1713

Este documento foi criado de forma automática no dia 14 novembro 2019.

(c) NUPEE 


\section{Um resort na restinga de Maricá / RJ: modernização do território e destruição da pesca artesanal em uma área de proteção ambiental}

Territorial modernisation and artisanal fishing: the construction of a tourist resort in an environmental protection area in Maricá (Rio de Janeiro) Modernisation territoriale et destruction de la pêche artisanale:

l'implémentation d'un village touristique dans une aire de protection environnementale à Maricá (Rio de Janeiro)

Modernización del territorio y destrucción de la pesca artesanal: la implantación de un resort en el área de protección ambiental de Marica-Río de Janeiro

Erich Moura Soares de Souza

\section{INTRODUÇÃO}

1 As atividades da pesca artesanal no Brasil convivem com movimentos de rápida modernização dos sistemas de produção de pescado. Tal transformação impõe necessidades de adaptações técnicas dos grupos que vivem desta atividade e que estiveram presentes em todas as etapas da história da formação territorial do Brasil. As técnicas de pesca dos povos indígenas foram ao longo do tempo transmitidas aos caiçaras, aos quilombolas entre outros. Contudo, ao mesmo tempo em que se modernizaram as atividades, a permanência das práticas "tradicionais" demonstra que a pesca artesanal ainda é uma importante atividade econômica, base de sustento e de trabalho para a sociedade.

Portanto, as formas de lutas de resistências e a defesa das comunidades pesqueiras que lutam contra a precarização do trabalho constituem assuntos relevantes para debate. 0 
caso dos pescadores artesanais que vivem na área conhecida como Zacarias, no município de Maricá-RJ, herdeiros de uma atividade centenária no local, é um exemplo a destacar. Os mesmos habitam uma restinga onde há diversos interesses políticoeconômicos e, em grande extensão, essa região é legalmente protegida - por ali existir fauna, flora endêmicas e reprodução de animais migratórios. Desse modo, a maior parte da restinga é considerada como Área de Proteção Ambiental (APA), uma Unidade de Conservação da Natureza (UC) que tem por objetivo a conservação da diversidade de ambientes, de espécies e de processos naturais.

Milton Santos apresenta esse movimento de renovação permanente das técnicas e a inclusão de novos instrumentos produtivos de modernização, e a caracteriza por "um conjunto coerente de elementos de ordem econômica, social, política e moral, que constituem um verdadeiro sistema" (SANTOS, 2008, p. 31). Segundo o autor, trata-se de um conjunto de inovações importantes para a definição de períodos históricos, pois concentram as principais forças que dividem as atividades econômicas dos países subdesenvolvidos.

4 A referência à modernização também pode ser considerada na inclusão de um processo de transformação do uso de um território, que altera hábitos e impõe uma nova ordem e uma nova função social na ocupação de uma determinada área. No caso de Maricá, o projeto do resort denominado por "Complexo Turístico-Residencial Fazenda de São Bento da Lagoa" é considerado por nós como um elemento transformador no uso do território e parte de um movimento de organização do espaço metropolitano no Rio de Janeiro.

5 O resort é um projeto imobiliário-turístico de capital espanhol que, ao longo de 8 anos, procura tirar proveito do potencial de crescimento do mercado imobiliário no entorno do megaempreendimento do polo petroquímico do Rio de Janeiro (Comperj), no município vizinho de Itaboraí e pela esdrúxula autorização para a utilização de APAMaricá para fins econômicos e turísticos. Trata-se de um complexo imobiliário de construções com fins hoteleiros, centro de comércio e serviços turísticos e de negócios. Uma modalidade de empreendimento presente nos litorais em diversos estados do Brasil, mas que cada vez mais se aproxima dos centros das metrópoles. No território fluminense já há inúmeras atividades desse setor, que são verificadas nos municípios de Búzios, Mangaratiba, Angra dos Reis e Paraty (MATIAS, 2011) e que podem ser aqui consideradas como inovação e modernizações de um mesmo ramo de atividades.

6 A APA-Maricá até o presente momento tem sido objeto de diversos usos compatíveis com a preservação da natureza, inclusive com forte relação de cooperação entre as comunidades. Entretanto a comunidade tradicional dos pescadores de Zacarias, que vive nessa área, passa a ser a principal vitima do resort; entre outros, como os moradores da cidade de Marica e adjacências que utilizam a área para lazer ou veraneio também passam a ser ignorados; além do grupo indígena da etnia guarani mbyá, que habita uma parte da APA desde 2013; e, em particular, a comunidade acadêmica que realiza pesquisas científicas desde a década de 1970 .

7 A APA-Maricá é usada por cientistas de diversas áreas acadêmicas, como a botânica, zoologia, hidrologia, geomorfologia, geologia, antropologia, geografia e climatologia, e é considerada como um dos maiores "laboratórios vivos" das universidades do estado e do país, devido a sua ampla diversidade biológica, fazendo com seja a mais pesquisada entre restingas no Brasil. ${ }^{1}$ 
8 Diversas mudanças legislativas vêm ocorrendo para a urbanização da APA, e consequentemente funcionaria para a entrada do resort. Em parte, tais modificações são demandas do executivo municipal e do legislativo estadual. o primeiro, em vez de defender o uso restrito do território, atualmente defende a construção do resort e ainda procura envolver os moradores na área da APA-Maricá como trabalhadores braçais, numa clara afronta à tradição da população local como pescadores, numa clara subordinação aos interesses do capital corporativo internacional proprietária do resort. Tal subordinação ocorre pela aprovação pela administração municipal de autorização da urbanização da área e a expulsão das comunidades tradicionais residentes nas terras da restinga.

9 Já o poder legislativo estadual autoriza a instalação do resort por meio da aprovação dos Estudos de Impacto ambiental e Relatório de Impacto ambiental (EIA/RIMA) apresentado pelo grupo espanhol há cerca de um ano. Nesses termos, verifica-se um conflito de cunho territorial, pois, o planejamento sob a responsabilidade do Estado conspira juntamente ao setor empresarial, ignorando as necessidades da sociedade local.

10 Assim, a dita modernização da APA-Maricá está centrada na dinâmica empresarial, com a transformação do espaço pesqueiro em unidades privadas que possam ser futuramente comercializadas. Não pode ser negligenciado o papel dos principais atores que, por um lado, competem para atrair o capital empresarial, na forma de concessões e especulações de terras e, de outro, a resistência da comunidade frente ao empreendimento de resort. Com isso, é necessário fazer uma leitura aprofundada sobre as ações hegemônicas, quase sempre justificadas pelo argumento de crescimento econômico e geração de emprego.

\section{Elementos referenciais acerca da modernização}

11 Para a análise dos conflitos sociais partimos da ideia de "modernização territorial" (SANTOS, 2008; SILVEIRA, 2003, 2014), focando a estreita relação dos projetos atuais de Maricá com o modo de vida e da urbanização social. Tal panorama remete às transformações das modernizações, vistas por SANTOS (1978) como elementos fundamentais de análise dos sistemas técnicos dos países subdesenvolvidos. O conflito principal gerado pela modernização dos territórios se dá através da implementação de mudanças nas relações de trabalho que se afirmam por implementações tecnológicas.

12 Nesse sentido, as modernizações "caracterizam-se primeiramente pelo fato de se organizarem e se reorganizarem em função de interesses distantes e mais frequentemente em escala mundial" (SANTOS, 1978:20). Segundo o autor é possível identificar que esse tipo de empreendimento atua segundo uma lógica da economia em rede, que denomina de verticalidades (Idem, 1994), e se impõe ações que podem ser consideradas redutoras/controladoras dos lugares que são o foco de empreendedores. Por serem intervenções que operam segundo lógicas econômicas de origem do capital internacional, produzem desigualdades e influem negativamente nas condições de renda e de atividades sociais no território local. Nesse sentido, a promessa da modernização que limita, restringe ou formata o acesso à produção e ao consumo da camada urbana, molda estruturas sócio-espaciais através de conflitos entre as camadas sociais. 
13 O conceito de modernização territorial, como assinala SILVEIRA (2014), trata de modernizações que conjugadas com outras variáveis socioeconômicas, "implicam um aumento das escalas de produção e circulação e uma nova expansão no território e na rede urbana" (SILVEIRA, 2014:167). Nesse sentido, as modernizações seriam, para autora, demandas da expansão do circuito superior da economia urbana ${ }^{2}$ e reações a forte tendência da internacionalização dos territórios com o auxílio dos Estados ${ }^{3}$. As modernizações territoriais são, sobretudo, seletivas, inerentes a "um novo modelo de produção, distribuição e consumo" (SANTOS, 2004, p. 55) e reconfiguram antigas relações de trabalho:

Quanto mais se expandem as formas modernas de trabalho e de organização no território, graças à base material contemporânea, mais se divide o trabalho sobre um meio já urbanizado. Crescem, concomitantemente, o número de agentes e ocupações na porção marginal do circuito superior e a divisão interurbana do trabalho. (Idem, op cit, p. 168)

14 Todavia, os circuitos da economia urbana não devem ser considerados somente em bases materiais. Isto é, apesar da ideia de "modernização" priorizar o foco econômico, os circuitos econômicos, segundo SILVEIRA (2014) atrelam de maneira relacional a condição social de agentes e os sujeitos do território usado (SANTOS, 1994). Vale ressaltar a ideia de "uso" ou "ação", conjugada ao território, pois entendemos no sentido de ação social, relacionada a determinadas tipologias com finalidades orientadas ou não por propósitos racionais coletivos (WEBER, 1999). São nesses termos os propósitos políticos os que melhor definem a ação social do território, pois envolvem relações de dominação e de poder.

Convém, então, aproximar as ideias dos autores já citados com aquilo que a literatura marxista nos trás como elementos fundamentais para a análise dos processos de modernizações territoriais. Embora existam divergências entre os teóricos que deram continuidade nas obras de Marx de maneira crítica e/ou os que se opuseram a uma chamada "ortodoxia", a partir dessa dualidade nos propomos a relacionar a ideia de modernização territorial ao trabalho artesanal sem negar a contribuição das oposições, já que entendemos como peças complementares.

16 Há na literatura marxista uma importante base teórica para leitura do processo de modernização, que entende a subordinação do trabalhador artesanal para o mercado urbano como a principal consequência de um conjunto de modificações das relações sociais. Uma primeira contribuição pode ser percebida quando Lênin (1985) afirma que a diferença do trabalho do espaço rural para o espaço urbano se focou inicialmente na dependência do trabalhador de ambos os espaços para um tipo de consumo e atividade. Com isso, o autor demonstra a subordinação do trabalhador camponês para o mercado urbano. Um processo que entendemos como um mecanismo constante de reorganização do trabalho e como consequência da afirmação de um sistema econômico baseado em modernizações. Tal diferença se percebe com a formação de uma massa trabalhadora subalterna aos interesses da classe burguesa.

17 A modernização se intensifica com a acumulação dos modos de produção nas cidades, geridas a partir de uma nova situação da classe burguesa, que se sustenta com a dominação das condições de trabalho dos camponeses e artesãos já que esses dominam, em quantidade, o abastecimento de alimentos para a sociedade.

18 Lênin (Idem) acredita que uma das principais características da precarização do trabalho é a contração de dívidas pelo camponês que, de uma maneira geral, é uma 
situação recorrente no ambiente de trabalho artesanal nos dias atuais. 0 autor ressalta que a busca por novas terras e trabalhos suplementares são parte integrante do processo de transformação dessas atividades.

Em diferentes espaços, as atividades tradicionais são modificadas por interesses das elites e para tal há um novo mercado determinando os diferentes modos de produção. Tal fato altera gradualmente as relações sociais e desintegra de maneira violenta os grupos artesanais tradicionais para novos usos territoriais.

Outro autor marxista, Kautsky (1986), também trata da questão da modernização. Ele afirma um caráter impositivo das atividades industriais urbanas junto à produção de mercadorias e que também resultam na expropriação dos meios de trabalho dos pequenos produtores ou artesãos. Pois estes últimos competem em desvantagem com o grande produtor a partir das novas necessidades então criadas pelas indústrias. Podemos afirmar que esses elementos contribuem no entendimento da modernização territorial como resultado da expulsão ou alienação do pescador artesanal dos seus modos de produção e de suas propriedades fundiárias, seja na modernização da pesca industrial - aquela proveniente de usos de embarcações de médio e grande porte, de grandes portos, de fácil circulação e de tecnologia sofisticada - seja na modernização da circulação e do comércio verticalizado.

21 Kautsky (Ibdem) afirma que a modernização se inicia com a transformação do sistema de comunicações em que a ampliação de estradas é um caso exemplar. O mesmo sentido pode ser visto em Milton Santos (2005), quando este assinala que quanto mais os meios de comunicação se desenvolvem, as cidades se tornam cada vez mais próximas. Nessa ótica, as áreas rurais ou de produção artesanais são cada vez mais consideradas um espaço dependente da modernização técnica, da forte integração e das demandas comerciais modeladoras do espaço urbano.

22 Com isso, é fundamental perceber com as novas mudanças de uso do território uma nova função as atividades das comunidades tradicionais. Territórios que estão constantemente sendo comandados por firmas "dizendo" o que se pode ou não produzir, que dominam agora a venda e o consumo dos grupos artesãos, planejando diretamente e indiretamente o território.

Por necessidade de se adaptar aos avanços técnicos da própria atividade de pesca, os pescadores de grande parte do litoral brasileiro se veem obrigados a adaptar-se a esse novo ambiente. Os primeiros impactos sentidos são os novos instrumentos de trabalho adquiridos pela indústria moderna, desde redes padronizadas, a incorporação de instrumentos eletrônicos na comercialização de seu pescado, maquinetas de cartão de crédito. Tudo que suas atividades não sejam excluídas da modernidade.

Nesse contexto, a resistência da comunidade de Zacarias pode ser entendida em duas dimensões. Resulta, por um lado, de adaptação das atividades aos novos meios e técnicas de produção; por outro lado, ocorre um processo de alienação territorial do trabalhador artesão, em face da implantação de novas técnicas sofisticadas para a expropriação dos meios de produção e da propriedade. Todavia em ambas as formas a pesca artesanal não é extinta e o pescador vive em função da luta pelo território. 


\section{A APA-Maricá e Pescadores de Zacarias}

25 A APA de Maricá localiza-se no litoral do estado do Rio de Janeiro, com cerca de $8 \mathrm{~km}$ de extensão, é formada pela ilha Cardosa, Ponta do Fundão e a restinga. Grande parte da vegetação é típica de restinga: cactos, bromélias, espécies diversas de gramíneas e arbustos de baixo porte conectados muitas vezes às pequenas dunas. Como informado em: LIS/ICICT/Fiocruz (2010),

“Aproximando-se do mar, a vegetação fica caracterizada por um duplo cordão arenoso coberto por dunas, ainda, bastante preservadas, que protegem a costa contra a forte ação erosiva do mar, tão violento nesse litoral. 0 cordão mais interno, o primeiro é o mais antigo, têm aproximadamente sete mil anos e o externo, o segundo é o mais recente, com cerca de três mil anos." (idem, op cit)

Existe ali certo equilíbrio costeiro e a restinga promove a criação de microambientes facilitando o desenvolvimento de diversas formações vegetais que caracterizam este complexo ecossistema de restinga. (Idem, op cit)

Atualmente os principais impactos ambientais se situam em trechos onde estão presentes a disposição inadequada de lixo, o desmatamento e o despejo ilegal de esgoto na lagoa. Assim, os empreendedores do resort afirmam que existe, em grande parte, áreas degradadas e, por isso, passíveis de intervenção de capital privado que seriam para eles uma forma de preservação. Entretanto um resort pode alterar de forma irreversível tal sistema, onde acarretaria um desequilíbrio no transporte de sedimentos, no que diz respeito aos cordões arenosos. Com isso poderia ocorrer um acúmulo de sedimentos em certa região e excessiva ação erosiva nas partes mais próximas do mar, além de diversos outros impactos mencionados nas audiências públicas e nos jornais por ambientalistas e por pesquisadores. A área ainda possui diversificadas espécies de flora (cerca de 408 espécies) e fauna endêmicas, que estão ameaçadas de extinção, sítios arqueológicos, infinidade de recursos minerais. A APAMaricá resume um abrangente patrimônio e biodiversidade.

29 A preservação desta área já vem ocorrendo há muitos anos. À medida que as organizações ambientais se comunicam com os pescadores no sentido de criar uma cooperação sobre o uso da APA-Maricá, os pescadores se dão conta que é preciso um maior cuidado com o uso da natureza e isso se inclui como importante pauta de debate na Associação de Pescadores de Zacarias (ACCLAPEZ). A pesca artesanal ao redor desse território se inclui na lagoa e algumas vezes no mar. Todo o trabalho com pesca desses dois ambientes e da restinga para ser separado o peixe, limpo e vendido na aldeia. A utilização em conjunto desses ambientes são motivos suficientes para que se considere a preservação como fator fundamental.

Todavia essa relação entre os grupos nem sempre é harmoniosa e os conflitos e a luta pela permanência na área da APA-Marica já são antigos. Ao conversar com os pescadores, os mesmos relatam que há um relativo isolamento da comunidade de pescadores das demandas públicas, o governo desde sempre dificultou a inclusão de serviços básicos na vila dos pescadores. Esse isolamento fazia parte da estratégia de controle dos governos que sucederam o poder municipal, como uma forma de estimular a evasão dos pescadores de seus terrenos. Suas casas, até pouco tempo atrás, não tinham luz, não tinham canalização de esgoto e diversas vezes os pescadores foram ameaçados de serem expulsos por não terem título de propriedade. Grande parte da 
área em que moram pertencia à antiga Fazenda São Bento da Lagoa que atualmente foi vendida aos proprietários do resort.

Outro problema ambiental que se destaca é quando a maioria dos pescadores luta para que não se asfalte Zacarias, porque conhecem a vantagem comercial da urbanização na APA-Maricá para o capital especulativo, enquanto uma pequena parte é estimulada a adequar totalmente o ambiente à cidade. Essa competição é introduzida quando os pescadores são obrigados a comprar redes leves e rápidas de fabricar, barco a motor etc, tudo fabricado pela grande indústria a preço elevado para o pescador. As formas de crédito e de produção são totalmente desiguais em se tratando entre diferença de modos de produção.

No mesmo sentido, recorremos a um comentário gerado entre os pescadores: "Não se pesca na lagoa como antigamente, constantemente muito peixe morre por causa do esgoto vindo das casas que não constroem sumidouro" (arquivo do autor). São evidentes os estragos causados pelo esgoto não tratado, pela crescente expansão de casas em torno da lagoa e, principalmente, ao redor dos rios que desaguam neste ambiente, quando aparecem enormes quantidades de espuma por causa do excesso de matéria orgânica de origem doméstica. Também não existe pesca em grande parte da lagoa por causa redução atual na entrada de peixes em pontos de despejo de esgoto. Com isso reduz-se o número de famílias que vivem somente da pesca, como também o número de pescadores amparados pelo auxílio defeso já que estes procuram somar as suas rendas outras formas de trabalho formais.

Há alguns anos, as esferas ambientais incluíam o pescador como extrativista e não como preservador, a ideia de "pescador artesanal" era sinônima de "depredador da natureza", termo esse muitas vezes presente no discurso de defesa do meio ambiente, de modo a determinar quem poderia usar as riquezas naturais. $O$ cotidiano vivido pelos pescadores de Zacarias contraria essa ideia: eles demonstram amplo conhecimento sobre a diversidade de vida na restinga e a preservação. Segundo os mesmos, quando os empreendedores do resort solicitaram a visita técnica na restinga para a elaboração do EIA, imediatamente solicitaram os pescadores como guias, para descrição da biodiversidade da APA-Maricá. Naquele momento os biólogos e demais analistas do projeto perguntavam o nome das espécies de aves e repteis e onde elas viviam, o que era motivo de divertimento entre os pescadores - por terem esse conhecimento desde cedo e saber que cada vida presente naquele ambiente é extremamente importante para se preservar o todo.

Os períodos de defeso são fases em que as espécies se reproduzem e por isso alguns pescadores não podem pescar recebendo um auxílio governamental para compensar as perdas e permitir a sobrevivência de sua família. Nesse momento há um profundo respeito entre os pescadores quanto à restrição para não pescar, principalmente no canal da lagoa, que funciona como passagem de diversas espécies para a reprodução. Nesse período buscam se ocupar com outras atividades econômicas informais, pois sabem que a pesca nesse período geraria o fim da atividade no futuro. É importante frisar que a pesca praticada por esta aldeia existe a mais de 200 anos.

Recentemente vem ocorrendo uma ocupação de algumas partes da APA-Maricá de maneira descontrolada. Alguns moradores vindos de outros lugares compram terras de grileiros e constroem moradias próximas as casas dos pescadores. A maior parte desses moradores talvez que não seja contra a construção do resort, pois vêm seus terrenos se valorizarem com o empreendimento. Uma possível explicação para esse surgimento 
pode estar relacionada à valorização vislumbrada com a promessa do resort e pela especulação imobiliária, trazendo novos moradores dispostos a revender futuramente o lote usado ou serem ressarcidos pelos donos do resort ou pelo Estado. Todavia essas novas formas de ocupação descaracterizam a luta dos pescadores e dos defensores da APA-Maricá, criando falsas correlações entre as vendas ilegais e o movimento organizado pelos pescadores.

Há ainda uma preocupação com a ocupação dos indígenas que se torna foco de beneficiamento do governo acirrando cada vez mais o conflito, pois este último componente concede privilégios aos indígenas, mas não reconhece a propriedade de Zacarias como pertencente aos pescadores. Para os indígenas o governo se apresenta como defensor de minorias, prometendo ofertas (principalmente aos seus líderes) e incluir os indígenas em atrações turísticas, disponibilizando documentos de reconhecimento de propriedade, enquanto aos pescadores forçam, muitas vezes, via assédio aos seus representantes, a revenda de seus terrenos.

Esse tipo de desmembramento político não é novo, ZIBECHI (2012) aponta que a estratégia de colocar um representante de um movimento social como culpado de uma retaliação promovida pelo governo faz parte de um modelo que promete criar potências. Fazem parte também da clássica expropriação do trabalho mencionada por Kautsky (1985), quanto se espera uma desapropriação voluntária do território ou uma incorporação submissa dos trabalhadores ao projeto de resort.

\section{Breve análise do projeto de resort}

O projeto "Complexo Turístico-Residencial Fazenda de São Bento da Lagoa" vem sendo modificado à medida que não consegue aval judicial para ser implementado. Em seus primórdios, de 2007 a 2010, o grupo espanhol afirmava pretender ocupar 10\% da área da APA, constituindo por "moradias de luxo (condomínio, casas e prédios), marina privada com capacidade para 1.000 embarcações, grandes zonas desportivas (campo de golfe), spa, teatro, parque empresarial, piscinas, centro comercial, hotéis, para aproximadamente 95 mil habitantes." (MATIAS, p. 60, 2010)

Naquele momento estava previsto um investimento na ordem de U\$ 4 bilhões, e dentre esse montante, $R \$ 320$ milhões seriam investidos em saneamento básico - tratamento de água e esgoto. (Idem, Op cit)

A figura 1 ilustra a imagem de percentagem e ocupação do projeto na área em questão: 


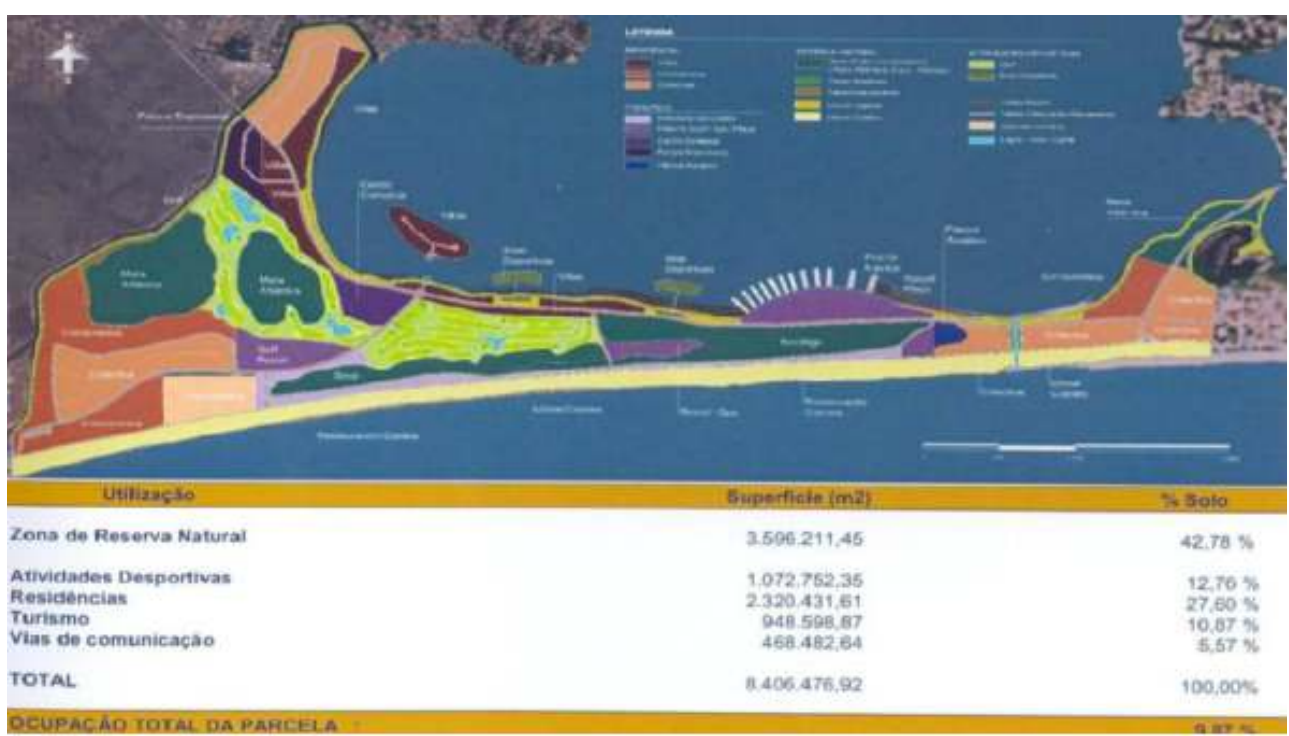

Fonte: FREIRE, 2011.

Todavia, em uma análise georreferenciada do mapa apresentado constatamos ${ }^{4}$ que a área a ser ocupada era muito maior do que a apresentada (Tabela 1 e Figura 2). Pelo zoneamento criado pela legislação estadual, a chamada Zona de Ocupação Controlada (ZOC), onde seriam feitas construções, compreendia cerca de $21 \%$ da APA e a Zona de Preservação de Vida Silvestre (ZPVS), que o projeto pretendia não alterar, pois haveria mais espécies de animais e correspondia a quase $58 \%$, sua maior parte era a faixa de areia da praia. A área de transição, Zona de Conservação de Vida Silvestre (ZPVS), onde poderia sofrer um "pequena" alteração ambiental, por consequência de esportes como o golfe, correspondia a quase $23 \%$. Em síntese, a ocupação real que seria utilizada pelo projeto era na ordem de $42 \%$ e não $10 \%$ como afirmavam.

Tabela 1 - percentual da área do zoneamento

\begin{tabular}{|c|c|c|c|}
\hline SIGLA & CNT SIGLA & SUM ÁREA & PERCENTUAL (\%) \\
\hline ZCVS & 5 & 2191850 & 22,08313 \\
\hline ZOC & 5 & 1994161 & 20,0914 \\
\hline ZPVS & 6 & 5739437 & 57,82547 \\
\hline
\end{tabular}

Fonte: FREIRE, 2011. 
Figura 2 - Georreferenciamento do resort a partir de imagem de satélite

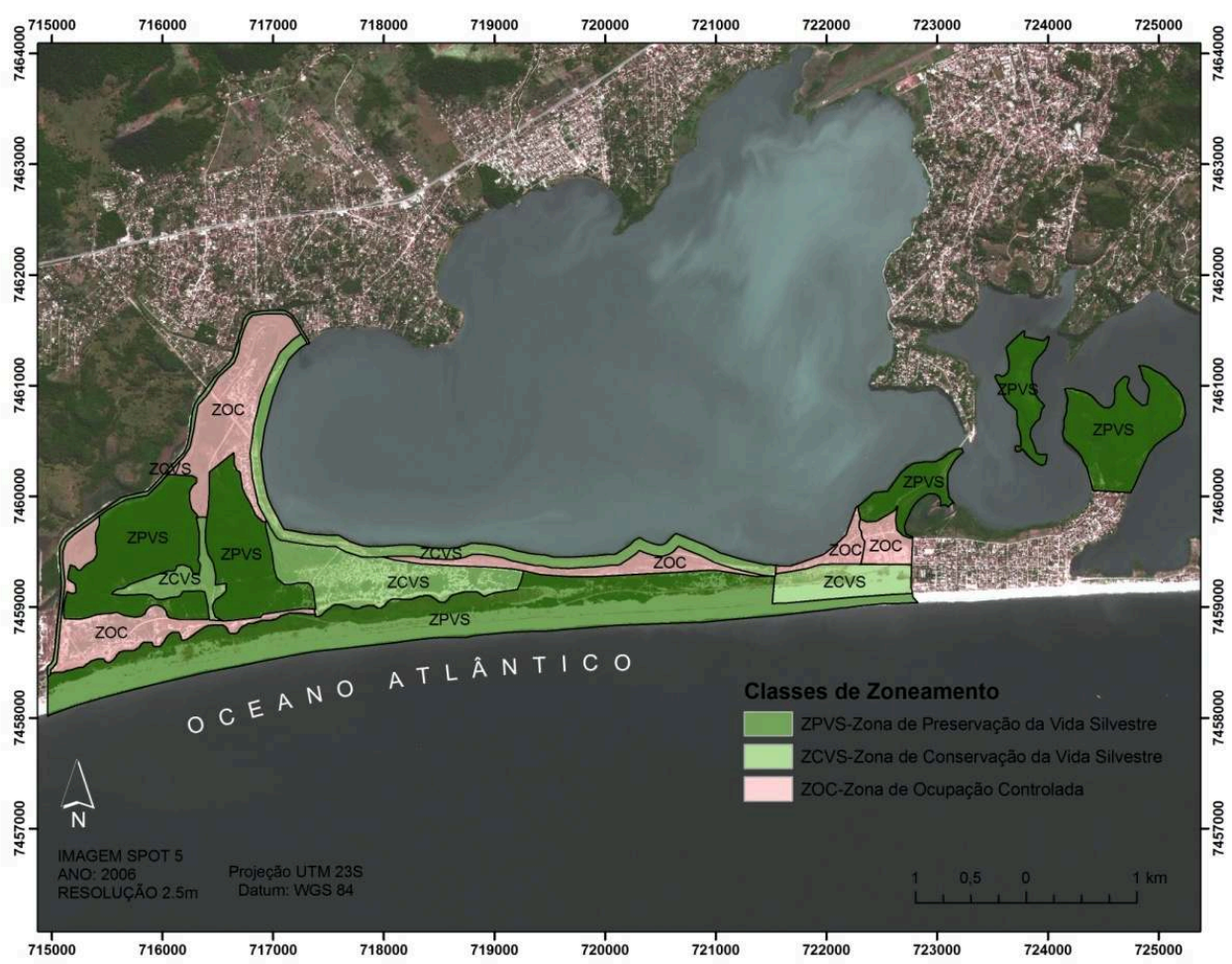

Fonte: FREIRE, 2011.

41 O projeto atual apresentado ao INEA (IDB Brasil, 2014), comparado ao anterior, prevê uma pequena diferenciação nas formas de intervenção, como ilustram as Figuras 3 e 4 onde são perceptíveis a inclusão de condomínios nas ZOCs. 0 atual projeto é mais discreto, pois não menciona claramente a percentagem de ocupação por zona, entretanto comparando as figuras 2, 3 e 4, vemos que as áreas com vegetação nas ZOCs, na Figura 4, são encobertas por manchas verdes, encobrindo o impacto real da urbanização.

O novo projeto prevê uma movimentação de 43.035 de pessoas (população fixa, flutuante e flutuante itinerante) em seu EIA, contrastando também com a população deste município, que é estimada em 140 mil habitantes - fixa e "pendular" (IBGE, 2010). Conclui-se que a população no resort será equivalente a $30 \%$ de toda população de Maricá contabilizada em 2010. 
Figura 3 - Mapa de ocupação do EIA (IDB, 2014) apresentado ao INEA

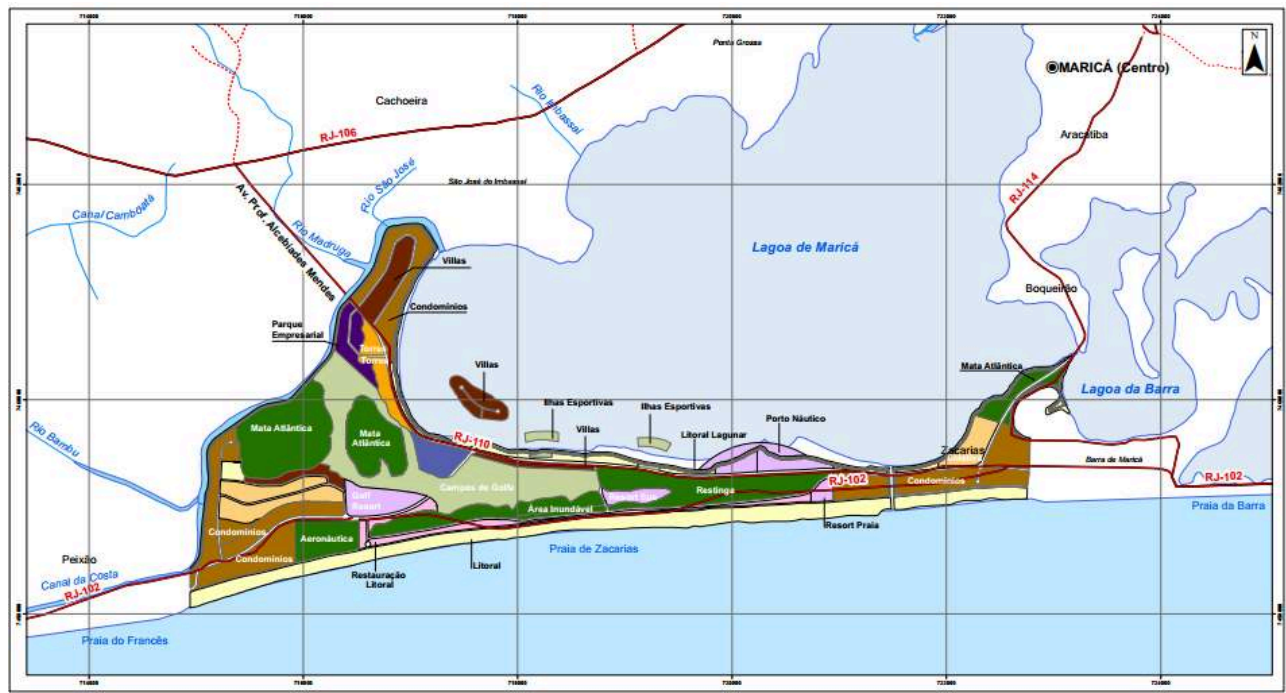

Fonte: IDB (2014).

Figura 4- Imagem de satélite editada no EIA (IDB, 2014) apresentado ao INEA

\section{Empreendimento Sustentável}

(RPPN, reagrupação fundiária e desarrolho turistico-residencial).

\section{IDB}

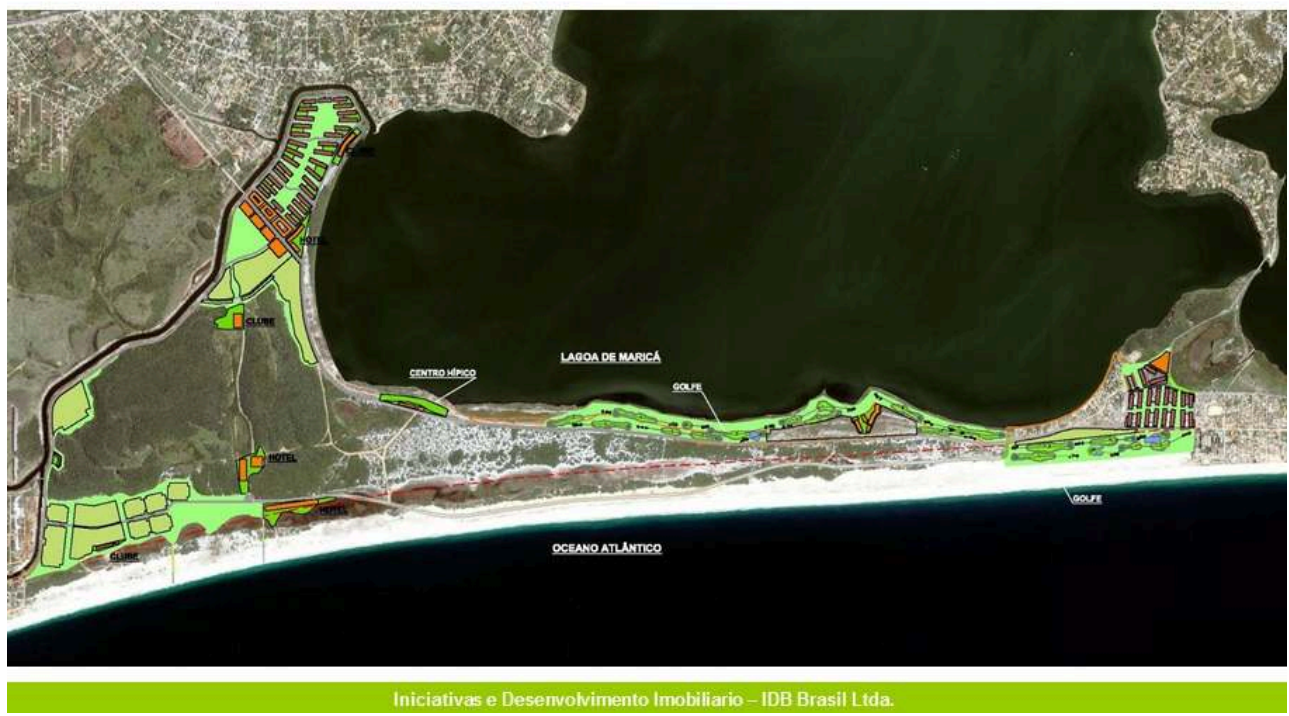

FONTE: INEA, 2014.

No quadro político, nota-se novos estímulos sobre a autenticidade do modo de vida dos pescadores artesanais, comandados pelos agentes de produção do espaço geográfico (Arlete Rodrigues, 2011), que consideramos aqui como os empreendedores do resort, quando esses deslocam a responsabilidade do impacto do modo de produção capitalista para os prováveis "consumidores" dos empreendimentos. Isto é, além do resort pretender impor um novo status aos pescadores (consumidores), este cria uma funcionalidade de legitimação para a sua implementação. Pois, nesse caso, aqueles que 
são colocados como os consumidores sempre foram tratados como os principais "culpados" da dilapidação ambiental para escamotear a responsabilidade dos agentes de produção. Para ilustrar a questão, Rodrigues afirma:

O deslocamento discursivo da produção para o consumo oculta as classes sociais, que passam a ser distinguidas como "classes de renda" e "classes de consumidores". Enquanto a produção é concretizada no espaço geográfico, o "consumo" é remetido ao indivíduo. Não há referencia ao comércio, ao lugar de troca, mas ao consumidor. Como pode ser ele o responsável pela dilapidação ambiental, se não é quem escolhe o que reproduzir? (RODRIGUES, 2011, p. 212)

Não custaria para que o resort seja legitimado por uma falsa necessidade do seu uso. Ainda que os pescadores artesanais quisessem ser fazer parte do projeto de resort na forma de trabalhadores ou consumidores (nossa pesquisa mostra que a grande maioria sequer foi solicitada), teriam que se adaptar a um padrão soft que os empreendedores buscam para o mercado hoteleiro. E é provável que este padrão se oferta para um consumo elitizado de um público internacional.

É ainda grave a ação do governo em relação ao empreendimento, evidenciada pelo descumprimento de leis de esfera federal e estadual, quando a FEEMA (atual INEA) cria o zoneamento da área em 2007, ignorando a opinião dos pescadores e da comunidade científica e indicando seu posicionamento sobre o resort. Isto gerou um processo em tramitação que está sob a responsabilidade do Ministério Público do Rio de Janeiro.

O governo municipal já foi a favor de que a APA se tornasse um parque - e um parque significa mais restrições de uso - e o INEA, durante certo período, já questionou o empreendimento, como ilustra a Figura 5, por isso é contraditório que ambos se unam em favor de um empreendimento, aparentemente, mais brando.

Figura 6 - Posição do INEA em 2011

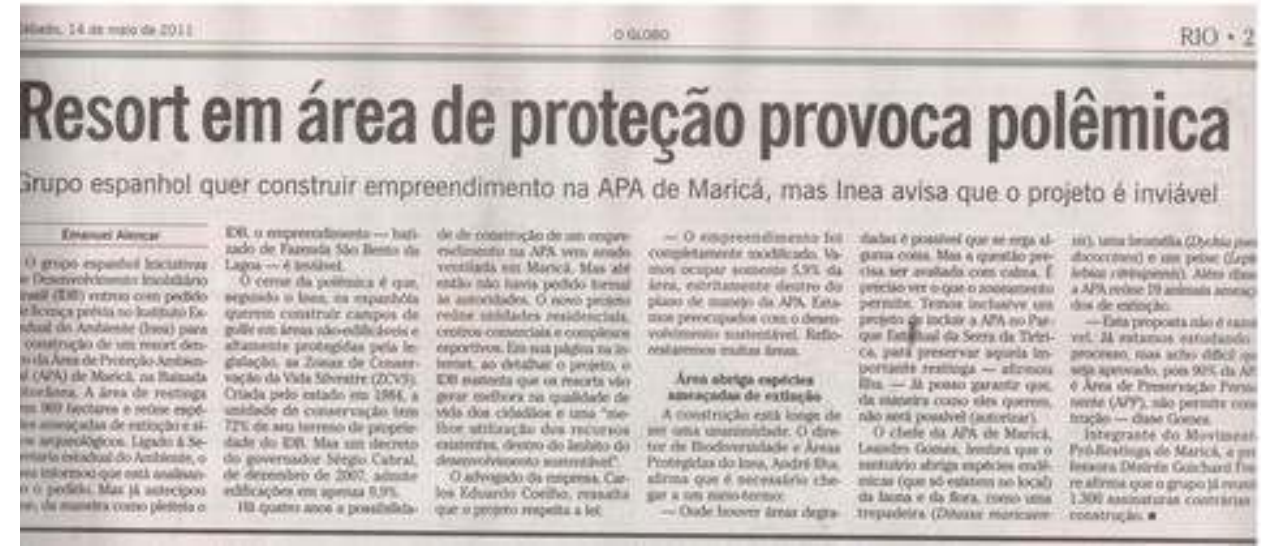

Fonte: O Globo, 2011.

Em diversas leituras constata-se a associação do Estado com a classe dominante, evidenciando que um grupo de alto poder aquisitivo quase sempre busca esse tipo de relação (ZIBECH, 2012; OLIVEIRA, 1975). Concordamos com as ponderações de Francisco de Oliveira (1975) quando este aponta que existe uma estratégia de reprodução políticoeconômica percebida na estreita relação do Estado capitalista brasileiro com perpetuação da luta de classes. Nos dias atuais, essa temática ainda é pouco analisada, principalmente quando são conflitos que envolvem as grandes empresas, o Estado, comunidades tradicionais e a decisão sobre o uso de riquezas naturais. 

empreendedores a ordem de 8 bilhões) e que, provavelmente, não deve ser a única ferramenta de atração de grandes corporações. Poderíamos, então, dizer que a construção do resort pretende se intensificar como um novo marco de valorização turístico-imobiliária em territórios de comunidades tradicionais do Leste

Oliveira (1978) ainda afirma que a estrutura de poder do Estado brasileiro vem sendo reproduzida pelos grupos hegemônicos a fim de criar e manter no poder uma classe econômica. Nesse caso, os projetos político-econômicos brasileiros, durante o fim do século XX, criaram uma estrutura para uma classe de alto poder de consumo e aquisitivo inerente ao avanço do capitalismo no Brasil, gerando tradições de relações entre a burguesia e o Estado.

A respeito do papel do Estado em conflitos socioambientais, Zhouri e Laschefski (2011) ilustram uma outra questão:

A presença do Estado, nos diferentes casos, mostra-se carregada de dubiedade: de um lado, surge com implementos das políticas conservacionistas autocráticas que acirram conflitos ambientais; de outro, surge como mediador que, por vezes, se posta ao lado das populações atingidas (p. 17)

O mesmo ocorre com as instâncias responsáveis pela APA-Maricá, isto é, quando as decisões do poder público são alteradas vertiginosamente. $\mathrm{E}$ a atualidade mostra que esse mesmo processo vem ocorrendo nos centros das cidades da região metropolitana do estado do Rio de Janeiro, com o despejo de população de baixa renda dando lugar a eventos turísticos e projetos imobiliários. Alguns exemplos são as remoções imobiliárias na cidade do Rio de Janeiro justificadas pelo avanço do Projeto Porto Maravilha e das obras de infraestrutura para as Olimpíadas de 2016.

51 Para Rodrigues (2011), toda essa estratégia depende da diferença entre os status econômicos para que o Estado se posicione em favor dos agentes capitalistas. Quando, por exemplo, os setores imobiliários, mesmo quando não cumprem a legislação ambiental, são, para o Estado, promotores do desenvolvimento "sustentável" e, por isso, do progresso econômico. Mas quando as populações de baixa renda são entendidas por esses agentes como promotoras do impacto ambiental são retiradas do seu território à força pelo Estado (Idem, Op Cit). A autora ainda afirma:

Os ocupantes de terra para a moradia estão nas "piores" áreas, aquelas que não interessam ao capital e são tidos como dilapidadores do "meio ambiente". Quando as áreas ocupadas passam a ter interesse para o capital, no entanto, a população é removida, criando conflitos mediados pelo Estado. (p. 214)

Nesses casos, o uso territorial é centrado na valorização comercial do "meio ambiente", que vem mascarando a perversidade do processo capitalista, sobretudo, com um falso discurso restaurador e preservacionista.

\section{Conclusão}

Em nossa análise vimos que a relação entre a modernização e o conflito estudados indica que as novas transformações objetivam a afirmação de um grupo no poder no território da APA-Maricá. Ao identificar que existem inúmeros grupos que usam o território com diferentes propósitos é estranho que o Estado se posicione em favor de um único grupo. Essa relação vem mostrar indícios para verificamos a expressiva influência do mercado imobiliário-turístico nos territórios pesqueiros de Maricá.

Indicou-se até agora o expressivo de investimento de capital transnacional (afirmam os turistico-imobiliária em territorios de comunidades tradicionis do Leste 
Metropolitano do estado do Rio de Janeiro? Há de considerar que, as essas investidas corroboram para a evolução do capitalismo e contrastam com a atividade de pesca artesanal.

Cabe lembrar que, ao longo dos últimos 8 anos de projeto, não se buscou acordo com os grupos que vão ser atingidos pelo resort, somente promessas de despejo ou de trabalhos braçais no empreendimento. Por isso (entre tantos outros fatores) percebemos que os pescadores artesanais são os protagonistas da mudança no cenário social, pois são quem efetivamente se põe contrários a esse tipo de modernização do território.

Concluímos que além do impacto social e econômico no mercado imobiliário, o exorbitante empreendimento poderá ocasionar uma série de impactos ambientais irreversíveis. É necessário, portanto, haver um acompanhamento crítico de tal processo com o intuito de analisar os efeitos do mesmo, além de pensar formas mais conscientes de uso e gestão do espaço urbano que não desintegrem o "modo de vida" dos grupos tradicionais.

\section{BIBLIOGRAFIA}

FREIRE, Désirée Guichard et all. Arquivo do autor. In: FREIRE, Désirée Guichard. Projeto de pesquisa "Conflitos socio-ambientais no Leste Metropolitano do Rio de Janeiro". 2009.

O GLOBO. Caderno Rio. 11 de Maio. 2011.

INEA. Estudo de Impacto Ambiental (EIA): Complexo Turístico-Residencial Fazenda de São Bento da Lagoa (Maricá - RJ). jan. de 2014. Disponível em: <http://www.inea.rj.gov.br/cs/ groups/public/documents/document/zwew/mdi5/ edisp/inea0029126.pdf>. Acesso em: 01 de jul. de 2014.

KAUTSKY, Carl. A questão agrária. São Paulo: Proposta editorial. 1986.

LÊNIN, Vladimir Ilitch. A desintegração do campesinato. São Paulo: Nova Cultural. 1985.

LIS/ICICT/Fiocruz. RJ - Pescadores artesanais da APA de Maricá lutam contra a instalação de mega resort. In: LIS/ICICT/Fiocruz. Mapa de conflitos envolvendo injustiça ambiental e saúde no Brasil. Disponível em: http://www.conflitoambiental.icict.fiocruz.br/index.php? pag=ficha\&cod=116. Acesso em jan. 2015. 2010.

MATIAS, Matheus Lage. "R" de Restinga ou de Resort? Disputas e conflitos socioambientais na APA de Maricá - RJ. Monografia de graduação. Rio de Janeiro: UERJ, 2010.

OLIVEIRA, Floriano Godinho. Território, Estado e Políticas Territoriais: análise das políticas de gestão do território e da recente expansão/reconcentração econômica nos espaços metropolitanos. In: XIII Coloquio Internacional de Geocrítica. Barcelona, 5-10 de mayo de 2014. Disponível em: http://vufind.uniovi.es/Record/ir-ART0000726523/UserComments.

OLIVEIRA, Floriano José Godinho de. Reestruturação econômica, poder público e desenvolvimento social: possibilidades de disputas e de recomposição do poder no território. In: Colóquio Internacional de Geocrítica, 9, 2007, Porto Alegre. Disponível em: http://www.ub.edu/ geocrit/9porto/floriano.htm 
OLIVEIRA, Floriano José Godinho de. Reestruturação produtiva, território e poder no estado do Rio de Janeiro. Rio de Janeiro: Garamond, 2008. 304p.

OLIVEIRA, Francisco de. A economia brasileira: crítica à razão dualista. In: LOPES, Juarez Rubens Brandão et al. Seleções CEBRAP 1: questionando a economia brasileira. v. 1. São Paulo: Brasiliense, 1975.

OLIVEIRA, Francisco de. O Crespúsculo do Capitalismo/Michael Harrington In: RIBEIRO, Darcy et al (Orgs) Encontros com a Civilização Brasileira. v. 1. Rio de Janeiro: Civilização Brasileira, 1978. p. 304-307.

RODRIGUES, Arlete Moysés. A matriz discursiva sobre o "meio ambiente": produção do espaço urbano - agentes, escalas, conflitos. In: A produção do espaço urbano. São Paulo: Contexto, 2010. p. 207-225.

SANTOS, Milton. 0 espaço dividido: os dois circuitos da economia urbana dos países subdesenvolvidos. 2 ed. São Paulo: EDUSP, 2008.

SANTOS, Milton. A urbanização brasileira. São Paulo: EDUSP, 2005.

SILVEIRA, María Laura. Argentina: território e globalização. São Paulo: Brasiliense, 2003.

SILVEIRA, Maria Laura. A natureza relacional dos circuitos da economia urbana. In: OLIVEIRA, Floriano Godinho de; et all (Orgs). Geografia urbana: ciência e ação política. Rio de Janeiro: Consequência, 2014. p. 155-178.

WEBER, Max. Economia e sociedade: fundamentos da sociologia compreensiva. 2 ed. Brasília: Editora Universidade de Brasília,1999. v. 2.

ZIBECHI, Raul. Brasil potência: entre a integração regional e um novo imperialismo. Rio de Janeiro: Consequência, 2012.

ZHOURI, Andréia; LASCHFSKI, Klemens. Desenvolvimento e conflitos ambientais: um novo campo de investigação. In: ZHOURI, Andréia; LASCHFSKI, Klemens (Org). Desenvolvimento e conflitos ambientais. Minas Gerais: UFMG, 2010. p. 11-31.

\section{NOTAS}

1. Constatação elaborada pelo projeto de pesquisa: "Conflitos socio-ambientais no Leste Metropolitano do Rio de Janeiro", coordenado por Désirée Guichard Freire, FFP- UERJ, em 2011.

2. Que basicamente compreende empresas de atividades modernas, como grandes empresas, bancos e outras atividades ligadas ao ramo da alta tecnologia.

3. SILVEIRA, María Laura. Argentina: território e globalização. São Paulo: Brasiliense, 2003.

4. Elaboração realizada pelo projeto de pesquisa: "Conflitos socio-ambientais no Leste Metropolitano do Rio de Janeiro", coordenado por Désirée Guichard Freire, FFP- UERJ, em 2011. 


\section{RESUMOS}

Tendo como base o conceito de modernização territorial proposto por Milton Santos, a pesquisa em curso analisa os impactos econômico, social e ambiental causados pela implantação de um projeto imobiliário tipo resort denominado Complexo Turístico-Residencial Fazenda de São Bento da Lagoa em uma Área de Proteção Ambiental (APA) no município de Maricá/Rio de Janeiro. Trata-se de espaço de extrema relevância, pois ali ocorre tanto a pesca artesanal da comunidade tradicional de Zacarias quanto uma série pesquisas científicas coordenadas por biólogos de todo o país. Resgatando a situação dos atingidos e a conjuntura que envolve tal implantação, examinamos também os Estudos de Impacto Ambiental (EIA) apresentado pelo grupo imobiliário ao Instituto Estadual do Ambiente (INEA), bem como a posição do governo do Estado do Rio de Janeiro nas audiências públicas ocorridas para a aprovação do resort.

Drawing on the Milton Santos's concept of territorial modernisation, this paper analyses the economic, social and environmental impacts provoked by the implementation of the project to build an estate complex called Touristic-Residential Complex Fazenda de São Bento da Lagoa within a zone of environmental protection of the Maricá (Rio de Janeiro) municipality. This project will impact an area of great environmental importance both for the traditional fishing of the Zacharias community and for the research made on the spot by biologists from all over Brazil. By analysing the situation of the impacted actors and the project's context, we question the Environmental Impact Studies (EIA) made by the estate group and presented by the Environmental Institute of the State (INEA), as well as the statements of the Rio de Janeiro State Government during pubic audits which preceded the project's approval.

À partir du concept de modernisation territoriale proposé par Milton Santos, cet article analyse les impacts économiques, sociaux et environnementaux provoqués par l'implémentation d'un projet immobilier nommé Complexe Touristique-Résidentiel Fazenda de São Bento da Lagoa, dans une aire de protection environnementale (APA) de la municipalité de Maricá (Rio de Janeiro). Ce projet empiète sur un espace d'énorme relevance environnementale à la fois pour la pêche traditionnelle de la communauté de Zacarias et pour des recherches menées là-bas par des biologistes de tout le pays. Par l'analyse de la situation des personnes affectées et du contexte de ce projet, nous questionnons les Études d'Impact Environnemental (EIA) réalisées par le groupe immobilier et présentées par l'Institut environnemental de l'État (INEA) ainsi que les positions exprimés par le gouvernement de l'État de Rio de Janeiro lors des auditions publiques qu'ont précédé l'approbation du projet.

Teniendo por base el concepto de modernización territorial propuesto por Milton Santos, la investigación en curso analiza los impactos económicos, sociales y ambientales causados en una Área de Protección Ambiental (APA) en el municipio de Marica (Estado de Río de Janeiro). Se trata de la implantación de un proyecto inmobiliario, en las características de un resort, denominado Complexo Turístico - Residencial Fazenda de São Bento da Lagoa en un espacio de extrema relevancia, pues allí se lleva a cabo tanto pesca artesanal de la comunidad tradicional de Zacarías como un conjunto de investigaciones científicas coordinadas por biólogos de todo Brasil. Rescatando la situación de afectados y la coyuntura que envuelve tal implementación, examinamos también los Estudios de Impacto Ambiental (EIA) presentado por el grupo Inmobiliario al Instituto Estatal del Ambiente (INEA), así como la posición del gobierno del Estado de Río de Janeiro en las audiencias públicas que ocurrieron para la aprobación del resort. 
ÍNDICE

Mots-clés: modernisation territoriale, resort, pêche artisanale, aire de protection environnementale, Maricá-Rio de Janeiro

Palavras-chave: modernização do território, resort, pesca artesanal, área de proteção ambiental, Maricá-RJ

Palabras claves: modernización territorial, resort, pesca artesanal, área de protección ambiental, Maricá-RJ

Keywords: territorial modernisation, resort, artisanal fishing, zone of environmental protection, Maricá-RJ

\section{AUTOR}

\section{ERICH MOURA SOARES DE SOUZA}

Universidade do Estado do Rio de Janeiro, Programa de Pós-Graduação em Geografia - FFP/UERJ, erichmoura@gmail.com 